\title{
Study of gynecological health of women with disabilities
}

\author{
Prajakta Ganesh Joshi' ${ }^{1 *}$ Ganesh Arun Joshi²
}

\begin{abstract}
${ }^{1}$ Department of Obstetrics and Gynecology, LN Medical College and Research Centre, Bhopal, Madhya Pradesh, India
\end{abstract} ${ }^{2}$ Department of Physical Medicine and Rehabilitation, CRC, Bhopal, Madhya Pradesh, India

Received: 15 September 2019

Accepted: 10 October 2019

\section{*Correspondence:}

Dr. Prajakta Ganesh Joshi,

E-mail: pjosh92@gmail.com

Copyright: () the author(s), publisher and licensee Medip Academy. This is an open-access article distributed under the terms of the Creative Commons Attribution Non-Commercial License, which permits unrestricted non-commercial use, distribution, and reproduction in any medium, provided the original work is properly cited.

\section{ABSTRACT}

Background: In routine gynaecological practice, women with disabilities are rarely seen. The available literature regarding gynaecological and obstetric issues of women with disabilities is scanty. Hence this study was designed on women with disabilities participating.

Methods: History and examination findings regarding gynaecological problems of 30 participants were collected.

Results: Results show that two third of the participants had normal menses while others had dysmenorrhea, oligomenorrhea, premenstrual syndrome, menorrhagia, infective vaginitis and urinary tract infection. 11 participants were married, out of which 2 had infertility. None of the participants had clinical findings suggestive of breast or cervical cancer. These findings are compared with available studies of similar type.

Conclusions: This study concludes recommending the need of special camps for women with disabilities with Gynaecologist on the panel.

Keywords: Anaemia, Disabled persons, Gynecology, Health services accessibility, Infertility, Women's health

\section{INTRODUCTION}

The proportion of disability in population is estimated between $2-15 \%$ in various national (Census of India, 2011) and international surveys (WHO, 2011). ${ }^{1,2}$ It is known that morbidity and mortality rates are more among the persons with disabilities as compared to the non disabled population. ${ }^{3}$ However in routine clinical practice of gynaecology, we rarely come across women with disabilities. This raises question about the access to gynaecological healthcare for women with disabilities and their health status. Hence this study was undertaken.

\section{METHODS}

The objective of this study was to describe the gynaecological health status of women with disabilities and their accessibility to health services focusing the preventive and therapeutic healthcare in gynaecology.
This study was undertaken at Composite Regional Centre for persons with disabilities (Divyangjan), Bhopal. The computerised data of the centre during calendar years 2015 and 2016 was sorted to dig out 333 women with disabilities above the age of 18 years. They were sent invitation over sms/telephonic call to participate in the study. A series of camps were conducted in the year 2017 for the participants at the centre. The inclusion criteria were - women with disability of any category, age 18 years or more at the time of registration, voluntary participation after receiving invitation from the authors. The exclusion criteria were women without significant disability, women who registered at the centre during any calendar year other than 2015 and 2016, and women who did not volunteer to come to the centre on the camp days. Following the ethical principles of World Medical Association Declaration of Helsinki, informed consent in prescribed format was taken from the participants. The second author evaluated the disability, categorized it and 
decided on inclusion of the participant. The first author took gynaecological history and health examination of the participants. Total of 30 women with disabilities participated in the study. The findings of the participants were noted in predesigned proforma where basic biodata, marital status, anthropometry, type of disability, chronic health condition, menstrual history, obstetric history, and accessibility to healthcare was evaluated. After examination, healthcare consultation and prescription was given. Nutritional supplements, antihelminthic and antibiotics were dispensed as indicated for gynaecological condition. If necessary, referral was done to hospital setup for healthcare purpose. The data was displayed in master chart and displayed in proportions. Statistical analysis was not intended in this study

\section{RESULTS}

The study included 30 participants between the age range of 18 to 75 years, out of which 11 each were having locomotor and hearing impairment while 7 had intellectual disability and 1 had multiple disabilities. Both female and male family members are providing help in maintaining personal hygiene of participants. Nine (37\%) participants were married out of which $2(18 \%)$ had primary infertility.

Four participants were not using any contraception. Out of the 9 married participants, 4 had home deliveries and 5 had hospital deliveries out of which one was a caesarean section. The gynaecological problems among the participants are described in figure (Figure 1). One participant was found to be hypertensive during the examination. Forty percent had pallor (one having severe pallor). None had palpable lump in the breasts or lymphadenopathy. Ten percent had urinary tract infection and $17 \%$ participants had infective vaginitis. All cases had normal cervical examinations. None of the participants had pelvic organ prolapse.

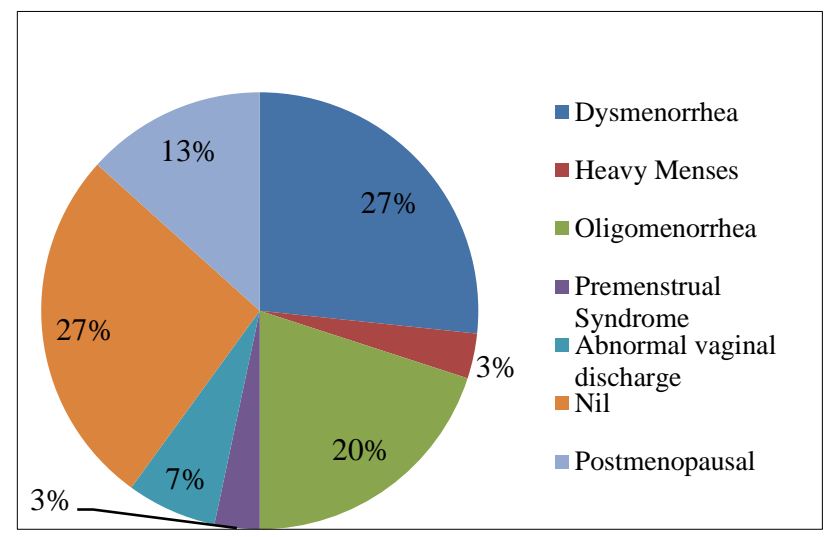

Figure 1: Gynaecological complaints.

\section{DISCUSSION}

A study from Philippines reports that communication difficulties affected provision of perinatal health services for women with disabilities. This was prominent factor as regards deaf and intellectually disabled women. The frustration of service providers in dealing with such situation results in poor clinical management. Due to lack of interpreters, family members were the source of information and thus the women with disabilities remained on side track during assessment and management. ${ }^{4}$ Participants of present study reported important role of family member as interpreter between the healthcare provider and the patient. It was noted that family members, especially husband and mother in law helped in postnatal care.

A review found lack of healthcare interventions to improve outcomes of pregnant women with disabilities. ${ }^{5}$ None of the participants was pregnant at the time of study. Their experiences during pregnancy, delivery and post natal care were enquired. They had used antenatal care facilities through the National Health Programs during their past pregnancies. Half of the participants had home deliveries. This suggests difficulty in accessing healthcare and communicating with healthcare facility.

The SIDE study found that women with disability had significantly lower experience of pregnancy, had more live children (indicating lesser use of contraception), complicated pregnancies and urinary tract infections were significantly higher but they utilized antenatal care equally as the non-disabled women. ${ }^{6}$ In our study, only one third participants were married suggesting lower likelihood of marriage and pregnancy among women with disabilities. Eighteen percent incidence of primary infertility amongst our participants is higher than that in general population (15\% as per WHO data). Half of our married participants were not using any contraception. Husbands of 2 participants used temporary methods of family planning. Permanent method of family planning by tubal sterilization was more common.

Recent reports state the prevalence of hypertension in more than one fourth to one third of women in India. ${ }^{7}$ One participant was found to be severely hypertensive and was given emergency antihypertensive drugs. The prevalence of anaemia is $50 \%$ in Indian women. ${ }^{8}$ In present study $40 \%$ had clinical anaemia (one having severe anaemia) probably because of poor dietary habits.

The prevalence of premenstrual syndrome is reported to be $18.4 \%$ in India. ${ }^{9}$ A community study has stated $45 \%$ cases having dysmenorrhea and $17 \%$ menorrhagia. ${ }^{10} \mathrm{~A}$ study in Iran reports $13 \%$ prevalence of oligomenorrhea. ${ }^{11}$ Out of the participants, $13 \%$ were postmenopausal. Among the remaining, 1 had premenstrual syndrome, $31 \%$ participants had dysmenorrhea, $23 \%$ had oligomenorrhea, and 1 participant had menorrhagia. Low incidence of premenstrual syndrome and dysmenorrhea might indicate inability to express discomfort and pain. Oligomenorrhea is a manifestation of anovulation resulting in primary infertility. 
Urinary tract infection affects $10 \%$ of women in the general population. ${ }^{12}$ Present study had the same finding. One third of the women in general community report symptoms suggestive of reproductive tract infection and half of them seek treatment. ${ }^{13}$ In present study, $17 \%$ participants reported abnormal vaginal discharge and $7 \%$ had vulval fungal infection. None of them had sought treatment for these symptoms till date. This low number might be related to higher number of unmarried participants. The prevalence of pelvic organ prolapse is $2 \%$ in general community while none of the participants had pelvic organ prolapse. ${ }^{14}$ Such a low figure indicates urgent need to ensure gynaecological healthcare including treatment for reproductive tract infection in women with disabilities.

A study during year 2012-2014 suggests that use of breast and cervical cancer screening is significantly low among women with disabilities. ${ }^{15}$ Another study mentions that women with locomotor disability had $40 \%$ lower Pap test rates. Hence they studied the cervical cancer screening by Pap smear over 12 year period of 1998 to 2010 and found that the rate was low among women with disabilities irrespective of the type of disability and concluded that there was little if any improvement after implementation of Disability Act in America. ${ }^{16}$ As women with disabilities are now living longer and hence risk of cancer is expected to increase a study found that health care workers, physical barriers and health insurance impair the access to cancer screening for women with disabilities. ${ }^{17}$ Two different studies in Canada found that women with disabilities have greatest inequalities in screening for cervical and breast cancers showing a strong association with the severity of disability. ${ }^{18,19}$ Any participant having palpable lymph nodes, abnormality on breast examination or on per-speculum and per-vaginal examination was not found. The participants were unaware about self breast examination, Pap smear examinations and hence were advised about these at regular intervals.

\section{CONCLUSION}

This study gives panoramic view of gynaecological healthcare services available for women with disabilities. Both male and female family members extend care in maintaining personal hygiene of the participants. There is lower likelihood of getting married and thereafter experiencing pregnancy in women with disabilities. The participants received antenatal care. However home delivery was common. Low use of contraception was noted amongst the participants. Infective vaginitis was less reported, but in those suffering from it, it remained untreated for long duration due to lack of access to gynaecologist. None of the participants were aware about screening methods for breast and cervical cancer. The study concludes low awareness and low access to gynaecological health care for women with disabilities.

\section{Recommendations}

The study recommends providing gynaecological healthcare for women with disabilities by organising special camps. This will help in early diagnosis and treatment of communicable and non-communicable diseases as well as obstetric and gynaecological care for the women with disabilities.

\section{ACKNOWLEDGMENTS}

The authors extend heartfelt thanks to the contribution of participating women with disabilities. The support extended by staff of Composite Regional Centre for persons with disabilities (Divyangjan), Bhopal is thankfully acknowledged. The authors acknowledge research grant by Ali Yavar Jung National Institute for Speech and Hearing Disabilities (Divyangjan), Mumbai to bring this topic to the fore of clinical and scientific community.

Funding: funding sources from Ali Yavar Jung National Institute for Speech and Hearing Disabilities, Mumbai Conflict of interest: None declared

Ethical approval: The study was approved by the Institutional Ethics Committee

\section{REFERENCES}

1. Ministry of Statistics and Programme Implementation. Disabled Persons in India: A statistical profile 2016. New Delhi: Social Statistics Divison, Ministry of Statistics and Programme Implementation, Government of India, 2016. Available at: http:// mospi. nic. In / sites / default /files/publication_reports/Disabled_persons_in_India 2016.pdf. Accessed on 12 $2^{\text {th }}$ January 2019.

2. World report on disability 2011. Manila: World Health Organization; 2011. p 27. Available at https://www.ncbi.nlm.nih.gov/books/NBK304079/. Accessed on $10^{\text {th }}$ March 2019.

3. Better health for people with disabilities: Infographic. Geneva: World Health Organization; 2015. Available at https:// www.who.int/ disabilities/ infographic/en/. Accessed on 10 ${ }^{\text {th }}$ March 2019.

4. Lee K, Devine A, Marco MJ, Zayas J, Atkinson GL, Vaughan C. Sexual and reproductive health services for women with disability: a qualitative study with service providers in the Philippines. BMC Womens Health. 2015;15:87.

5. Malouf R, Redshaw M, Kurinczuk JJ, Gray R. Systematic review of heath care interventions to improve outcomes for women with disability and their family during pregnancy, birth and postnatal period. BMC Preg Childbirth. 2014;14:58.

6. Murthy GV, John N, Sagar J. South India disability evidence study group. Reproductive health of women with and without disabilities in South India, the SIDE study (South India Disability Evidence) study: 
a case control study. BMC Womens Health. 2014; $14: 146$.

7. Gupta R. Trends in hypertension epidemiology in India. J Hum Hypertens. 2004;18(2):73-8.

8. Kaur K. Anaemia 'a silent killer' among women in India: present scenario. Euro $\mathbf{J}$ Zool Res. 2014;3(1):32-6.

9. Madhusudan RC, Navinchandra PB, Sachidanand TD, Ukabhai VA, Bhupendrabhai BR. Prevalence of premenstrual syndrome and premenstrual dysphoric disorder among college students of Bhavnagar, Gujarat. Indian J Psychiatry. 2016;58(2):164-70.

10. Laksham KB, Selvaraj R, Kar SS. Menstrual disorders and quality of life of women in an urban area of Puducherry: A community-based crosssectional study. J Family Med Prim Care. 2019;8(1):137-40.

11. Samani OR, Hashiani AA, Razavi M, Vesali S, Rezaeinejad M, Maroufizadeh S, et al. The prevalence of menstrual disorders in Iran: A systematic review and meta-analysis. Int $\mathrm{J}$ Reprod Biomed (Yazd). 2018;16(11):665-78.

12. Thakre SS, Dhakne SN, Thakre SB, Ughade SN. Hygiene practices and sexual activity associated with urinary tract infection in rural pregnant women of Nagpur, India. Indian $\mathrm{J}$ Med Microbiol. 2015;33:177-8.

13. Sharma D, Goel NK, Thakare MM. Prevalence of reproductive tract infection symptoms and treatmentseeking behavior among women: a community-based study. Indian $\mathbf{J}$ Sex Transm Dis AIDS. 2018;39(2):79-83.
14. Rao KB, Nayak SR, Kumar P, Kamath V, Kamath A. Prevalence of Pelvic Floor Dysfunction among Married Women of Udupi Taluk, Karnataka. India. J Women's Health Care. 2014;4:236.

15. Grobe FK, Shropshire WC, Zimmerman H, Brunt VJ, Betts A. Reach of the montana cancer control program to women with disabilities. J Community Health. 2016;41(3):650-7.

16. Iezzoni LI, Kurtz SG, Rao SR. Trends in pap testing over time for women with and without chronic disability. Am J Prev Med. 2016;50(2):210-9.

17. Ramjan L, Cotton A, Algoso M, Peters K. Barriers to breast and cervical cancer screening for women with physical disability: A review. Women Health. 2016;56(2):141-56.

18. Lofters A, Guilcher S, Glazier RH, Jaglal S, Voth J, Bayoumi AM. Screening for cervical cancer in women with disability and multimorbidity: a retrospective cohort study in Ontario, Canada. CMAJ Open. 2014;2(4):240-7.

19. Guilcher SJ, Lofters A, Glazier RH, Jaglal SB, Voth J, Bayoumi AM. Level of disability, multi-morbidity and breast cancer screening: does severity matter? Prev Med. 2014;67:193-8.

Cite this article as: Joshi PG, Joshi GA. Study of gynecological health of women with disabilities. Int J Reprod Contracept Obstet Gynecol 2019;8:4383-6. 